\title{
Leveraging Diversity in Community College Foreign Language Instruction
}

\author{
Weihsun Mao \\ Ohlone College
}

Diversity among students can be both a challenge and a resource. In this paper, I incorporate observations and experiences as a teacher in various settings of Mandarin language education to discuss the different types of diversity frequently encountered in the community college system, and how to install inclusive practices that celebrate "the world of difference" and improve the pedagogical experience. I will discuss how to bridge differences in age, ideology, technological ability, language, and professional backgrounds. These observations point out that diversity within the classroom can be leveraged for more effective learning outcomes and satisfactory student experiences in the context of foreign language instruction in the California Community College system.

\section{DIVERSITY IN THE CLASSROOM}

In an American broad-access community college, diversity in the student body abounds and occurs along multiple dimensions. The Mandarin classrooms, onsite and online, at Ohlone college, one of the campuses of the California community college system, have students who range widely in base language ability as well as in demographic background. There are students who have never heard Chinese before, who have grown up in Chinese households, who come from Asia, who come from the Americas. There are students who have drastically different cultural, social-economic, religious, and political backgrounds.

We pride ourselves on our richly diverse groups of students. To provide an example of how wide a variety our students' backgrounds are, I have randomly jotted down the backgrounds of 100 students from different years and appended to this paper. Here is a PowerPoint slide that provides a glimpse of how diverse our student body is: 


\section{FIGURE 1 \\ DIVERSE STUDENT BODY IN THE CLASSROOM}

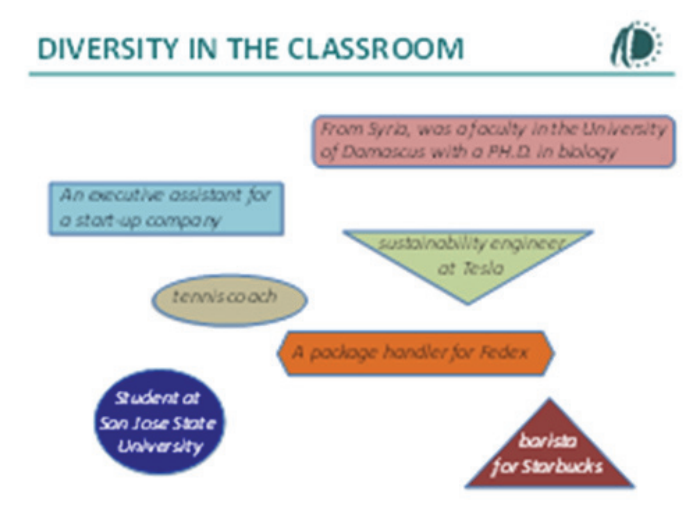

\section{HOW TO LEVERAGE DIVERSITY}

Clearly, the students of my Ohlone classes vary widely by age, academic background, socialeconomic background, religious and cultural background. This diversity is potentially a great asset to the class, but requires certain pedagogical practices on the part of the instructor to properly leverage how to shape opportunities for inclusive practice that celebrate "the world of difference." These observations will be based on my own experiences as a teacher in various settings of language education. Specifically, I will discuss strategies in a number of key contexts: one, how to create a collegial ambience; two, bridging the age divide; three, respecting religious and ideological differences; four, overcoming the fear of technology; five, connecting native and non-native speakers; and six, connecting adult learners and traditional college students.

\section{Breaking the Ice}

The first day of class is an extremely important session. Students walk into the classroom without knowing each other, often wondering whether they want to stay to take the class. To create a classroom environment to bind students together, I start the first day of class by introducing one or two ice-breaking activities - "Who Am I" and "Guess Which Statement Is False?" By playing these games, students get to know each other, from first and last names to hobbies, from interests to their places of birth. Without any conscious effort, students become more aware of the world they live in, but more importantly, they learn to appreciate and respect the diversity of their peers. As they leave the classroom, students often tell one another how eager they are to come back to class to find out "who everyone else is." Hearing this was a triumph because it meant that I successfully evoked a sense of connection and loosened the rigid conceptions of "other" people. I made sure my students came to see each other as classmates and unique individuals rather than stereotypes sequestered by insurmountable "differences."

\section{Breaking the Ice Online}

Likewise, in online classes, students also want to know about their fellow students. To launch the feeling of community, my online Mandarin courses begin with a getting-acquainted discussion post providing an opportunity to share something personal about oneself. Despite being an excitingly diverse group, course members find relatedness and connections, gaining knowledge of one another for mutual support.

Other discussion topics help weave additional connecting threads among the course members:

- Share an "aha!" moment you experienced while learning Mandarin

- Share one of your tips, tools or resources for learning Mandarin 
Inviting students to answer these questions has been a great strategy in creating student involvement and increasing confidence. It can be daunting for students to learn new and difficult material, and asking them to share their own knowledge, tips, and skills leads them to revisit their own mastery of the material, growing their confidence at the same time, resulting in positive and energizing experiences as well as insight-conducive environments.

\section{FIGURE 2 \\ STUDENTS SHARING “AHA” MOMENTS}
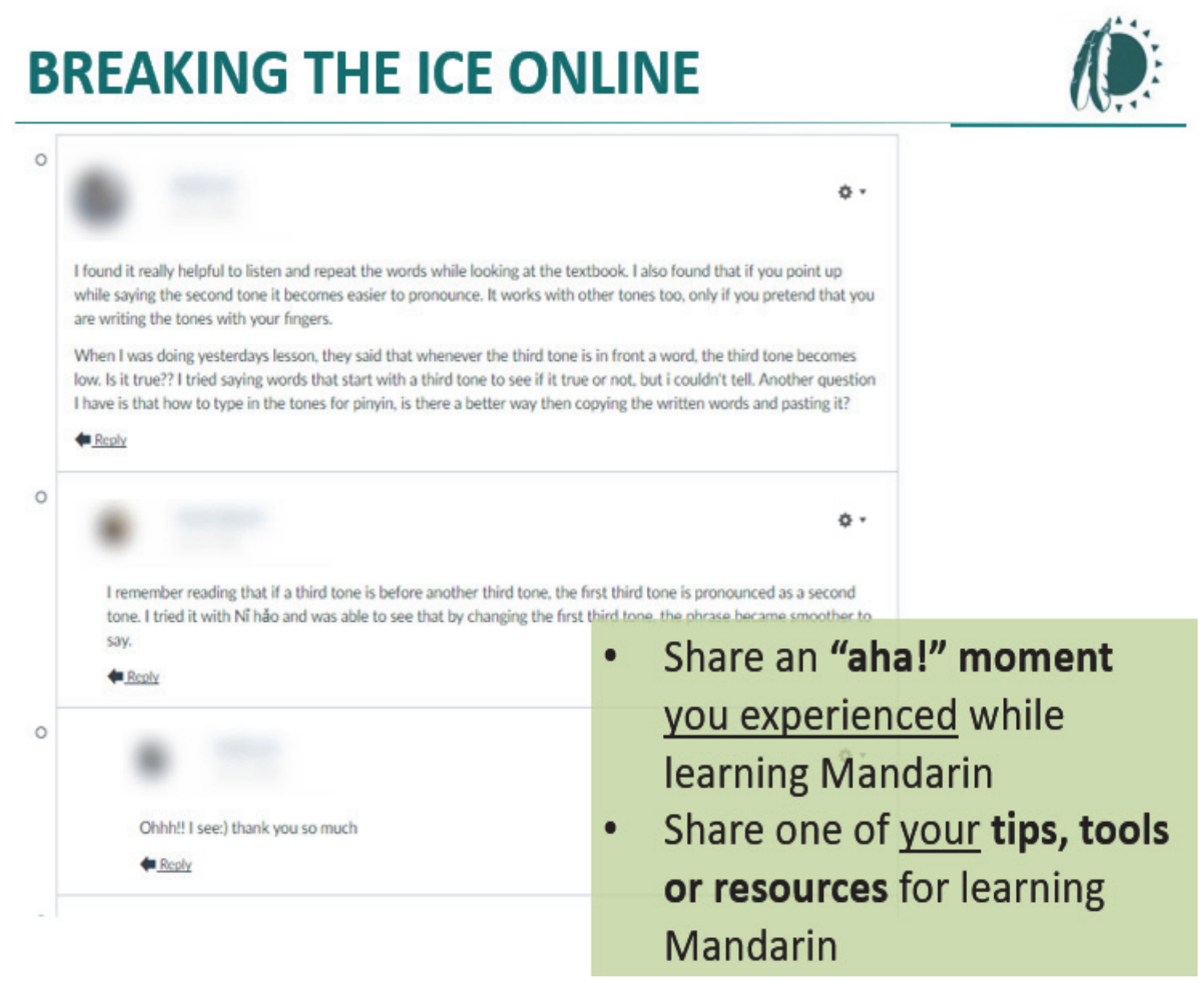

Students often greatly enjoy these discussions, where are an opportunity for students to get to know each other well despite the online setting. In fact, some students feel that online discussion boards allow them to know their peers better than traditional, on-campus classes. For example, one of my students told me: "It was really nice to get to know everyone through the discussions. I felt that I knew my classmates for this online class a little better than my classmates in my on-campus classes...."

\section{Online Conversations}

In fact, we can tally the total amount of interactions between students and their classmates using discussion boards. A typical thread would be equal to an hour-long conversation involving between three and four replies in a more than twenty-person class. This demonstrates how we can use classroom tools to encourage students to interact with each other, taking advantage of their diversity of viewpoints to generate sustained conversations. 


\section{ONLINE CONVERSATIONS}
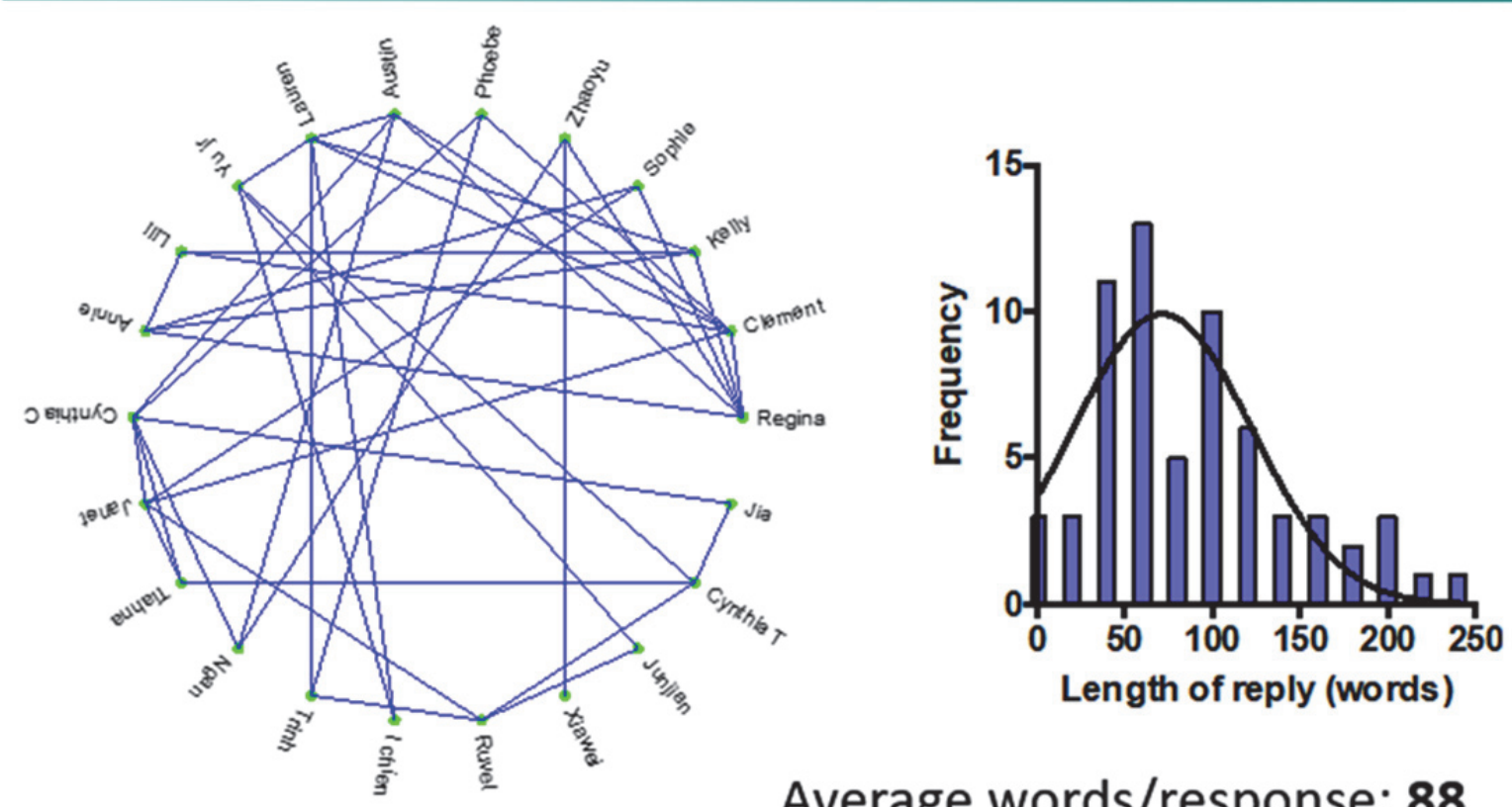

\section{Replies/student: $\mathbf{3 . 4}$}

\section{Average words/response: $\mathbf{8 8}$ Total duration of "conversation:" 57 minutes}

\section{Bridging the Age Gap}

Some of the students in my class are quite elderly. In fact, one year, we had a 68 -year-old lady who suffered an ischemic stroke that impaired her walking ability. In order to bridge the age gap, one of the techniques I implemented was role-playing a "family" in Mandarin Chinese. The 68-year-old lady volunteered to take the role of the grandma or matriarch, and every group in the class competed to have her on their group. This "family" role-playing had the dual effect of making my elderly student feel more actively included, as well as gave her the sense that this new curriculum we were learning had material in it that she could relate to.

\section{Embracing Religions and Ideologies}

My classroom is also an open environment that has students hailing from different ideologies and religions. My students are Christian, Jewish, Muslim, Buddhist, atheist, and more. When an issue of ideological difference arises, I find it important to first embrace the student's concerns, demonstrate my respect for their concern, offer alternatives, but, finally, gently challenge their assumptions.

Once, when I was briefing the class about the agenda for the day, I told the class that I was planning to play the movie "Tai Ji Zhang San Feng" in relation to the cultural topic of the concurrent lesson. A student came to me during recess and told me that she could not watch the violence that was part of the movie due to her Christian faith. I embraced her and told her that I both understood and respected her feelings and values; I also offered her an alternative learning task from watching the movie. After assuring her this liberty, I asked her whether she had watched this movie before, and she answered "no". 
Instead of avoiding the controversy at hand, I further asked her if she would mind me giving her a summary of the plot and themes of the movie. She seemed very intrigued and, after hearing the plot, decided to take a look at the movie together with the rest of the class. During the discussion that followed the movie, she voluntarily commented on how she enjoyed the movie and felt that the film's message was ultimately that of redemption. I was gratified that I could convince her to experience different values while maintaining respect for and understanding of her own.

\section{FIGURE 4}

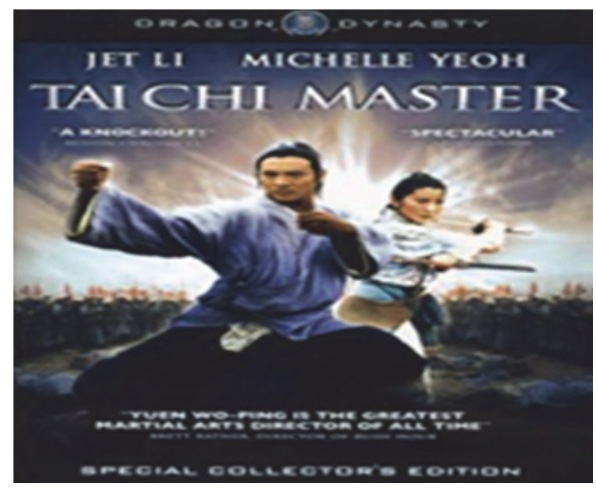

\section{Bridging the Tech Divide}

New technologies in support of language instruction have become more commonplace, including the teaching and learning of Mandarin Chinese. A wide range of technology uses, ranging from audio and video lectures and resources, PowerPoint (PPT) to network-based emails, chats, online discussions and conferences, have been identified as useful tools to both assist and enhance language learning. However, learners bring their own personalized and customized knowledge, skills, and attitudes to the class and their experiences and attitudes towards technology vary.

In each of my hybrid as well as fully online Mandarin Chinese classes, I have students who favor using technology and students who fear using technology. Those students who are comfortable with technology are at ease with online spaces and have an almost intuitive knowledge of electronic devices. They complete technology-based learning requirements quickly and without difficulty. I also have students who consider themselves "old schoolers", and young college students who are afraid that they are too young to keep up with the technology. As one said, "I am only 17 and haven't learned/ taken any online class [before]."

An example of a required usage of technology that is sometimes daunting to students is the implementation of pinyin input. Pinyin is the most widely used Mandarin Romanization system to sound out or spell out Chinese, and is widely utilized to input Chinese characters on computers and smart phones.

The pinyin system uses Roman letters as well as four tone marks to mark the four tones in Mandarin Chinese. A Mandarin syllable consists of a final/vowel, an initial/consonant and a tone. It is essential to complete the syllable with its tone mark in order to pronounce the right meaning of it. In spoken Chinese, there are many Chinese words whose meanings are differentiated solely by which of the four tones is assigned to them, so these tone marks are very important. These tones are written above the vowel in each syllable. However, typical word processing programs and Internet browsers cannot easily input these tones. As such, students need to install a Macro to enable pinyin input. This is sometimes difficult for students, and I once had a university professor in my class who was unable to properly install the Macro. One of my students, a college freshman, volunteered to help him, and throughout this process, the two of them used vocabulary they had learned in the class. For example: "Hey, Kenn (the name of my professor student), Nǐhăo (or hello), let me show you. Wǒmen kànyikàn. Let’s take a look." 
The technological expertise inherent in a diverse classroom can be leveraged to help less tech-savvy students overcome their discomfort with technology. Moreover, these moments can be transformed into opportunities to practice the curriculum they are learning.

\section{FIGURE 5}

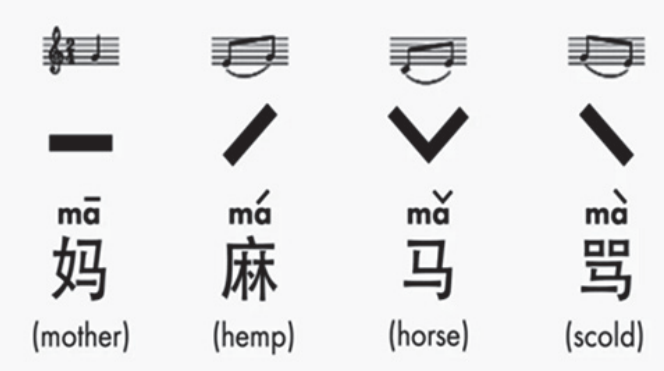

\section{Bridging NS and NNS}

There are native speaker students (abbreviated as NSs) and non-native speaker students (abbreviated as NNSs) in almost every Mandarin class I have taught. The native speaker students in my Mandarin classes are those who came to the US after some years of schooling since birth in China. This group of students wants to pick up and brush up their Chinese language after some time of disuse. This also includes heritage speakers, who were born in the United States and learned Mandarin, but may be at various stages of fluency. I also have international college students who recently came from China. This group of students takes the class mainly to accrue college credits for transfer to other colleges.

At the beginning of the semester, there is actually a substantial amount of friction between students who are highly proficient and those who are just beginning. Those who are highly proficient want to test out of the class; those who are just beginning resent the presence of those with a high aptitude.

Community colleges sometimes do not have the resources to provide classes with fine delineation of language aptitude, and so it becomes inevitable that students with very different starting levels have to sit in the same classroom.

The best way to resolve this tension is to purposefully pair NS and NNS together for classroom activities. This provides a number of benefits to both individuals in the pairing. This naturally exposes NNS to NS and accelerates their acquisition of the language. This also benefits the NS because NNS, with their outsider's approach to the foreign language, often ask insightful and unexpected questions about linguistic features that NS take for granted, much like Socrates during his interlocutions. For example:

- Why does the Chinese character 英 in the word 英雄 (hero) have the grass radical? What does grass have anything to do with hero?

英 is the essence of plants. 雄 is the spirit of animals. The combination of these two characters creates the word 英雄 (hero) that refers to prominent people. The ideogram 英 depicts a mature man $大$ in the midst of a large space $\boldsymbol{r}$, thick with vegetation $*$, suggesting a brave man in a jungle. Hence the grass radical, ${ }^{*}$, on top of the character 英.

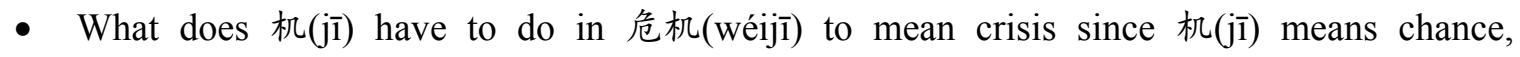
opportunity as we just learned?

The Chinese word for crisis, 危机 (wéijī), consists of two characters: 危 (wéi) and 机jī. These two characters come together as one semantic unit, or word, to mean crisis. The 
first character means danger and the second character means opportunity. The two characters in the word 危机 suggests that opportunity follows crisis, similar to the English idiom "the darkest hour is just before the dawn." However, unlike English, each

Chinese character encapsulates individual morphemes, or basic units of meaning.

- Why is 鱼香茄子 yúxiāngqiézi (eggplant with fish fragrant sauce) called this given it doesn't have fish in it?

Once upon a time, there was a business man in Sichuan. His family liked to eat fish very much, and they would prepare the fish with onions, ginger, garlic, wine, vinegar, soy sauce, etc. One night, the hostess of the family was frying an eggplant dish and she used leftover fish seasoning. Despite her initial expectation that such preparation would be far from delicious, her husband thought otherwise and swallowed handfuls before dinner even started. Although this famed dish does not have any fish, it is filled with fish aroma, hence the name 鱼香茄子 yúxiángqiézi (eggplant with fish fragrant sauce).

Even though they rarely question their own language and accept the way (how) it works, NS are challenged by these questions to articulate how all of these words got into the language and why the language works the way it does or why that rule exits. These peer interactions truly are a win-win situation for both Chinese NNSs and Chinese NSs. NS must respond to these questions by clarifying concepts and links to background knowledge, for which they need to switch between English and Chinese. Since many NS are concurrent ESL students, this enables them to practice their English at the same time.

Moreover, both NS and NNS compare and analyze the similarities and differences between their target and native languages, which greatly help deepen their comprehension not only of the topic but also of the various language aspects. Finally, the empathy they have gained from simultaneously occupying the role of language teacher and language learners promotes an environment conducive to learning. The rapport that has been built in the process positively influences their language learning experiences.

\section{Connecting with Adult Learners}

In recent decades the largest demographic adding to our Mandarin program enrollee numbers are the adult students. They are enrolled in a course - whether onsite or online - in which their peers - traditional college students - are fresh from high school. Many adult students may be more than twice the age of traditional college students. Despite the age difference, the adult learners and the traditional college students can complement and supplement each other in their academic endeavors.

Many adult students have decided to take a foreign language course, like Mandarin Chinese, out of their own volition. Some of them do so because they feel an interest in the subject or for personal enrichment. Others want to gain Chinese communication skills to do business or have better chances of advancement in their careers. Studies have shown that for the 18-24-year-old group, the encouragement of parents is a major factor of what they choose to study. Hearing their adult classmates talk about their motivations enables younger students to better appreciate the benefits and importance of studying a foreign language. Younger students are also exposed to the drive and determination of their older peers, which inspires them in turn to work harder.

Moreover, adult learners bring to class an incredible amount of knowledge and experience. Some of this knowledge is highly specialized or industry-related, such as health care, computer, financial services, real-estate, pharmaceuticals, marketing, manufacturing, or general knowledge, for example of photography, programming, cars, sports, crafts, electronics, and even other foreign languages. They generally have more things to share than their foreign language vocabulary allows. An interesting and rewarding exercise is to pair these adult learners with their younger counterparts. The two students, young and old, effectively work collaboratively to piece together the foreign language vocabulary to express the knowledge and/or stories that the adult learners have to share. 


\section{CONCLUDING REMARKS: INCLUSIVE EDUCATION IN A DIVERSE MANDARIN CLASSROOM}

Diversity has always been an integral part of our curriculum and classroom, and these anecdotes are records of its importance. Our differences in culture, race, occupation, age, gender, religion, sexual orientation, and physical ability become united in the classroom for the sake of learning. Increasing interpersonal interaction through specific classroom practices can result in greater positive performance from all participants. The outcome of experiencing increased interaction within a diverse classroom is the growth of open-minded individuals who embraces diversity and cultural awareness while simultaneously increasing language aptitude. Students of diverse background from all walks of life, all fields of work, and all corners of the world have the chance to learn from each other.

\section{REFERENCES}

Abbitt, J.T., \& Klett, M.D. (2007). Identifying influences on attitudes and self-efficacy beliefs towards technology integration among pre-service educators. Electronic Journal for the Integration of Technology in Education, 6(1), 28-42.

Adams, J., \& Corbett, A. (2010). Experiences of Traditional and Non-Traditional College Students A Quantitative Study of Experiences, Motivations and expectations Among Undergraduate Students. PERSPECTIVES, 2(1), Article 2.

Collins, A. (2017). What's Worth Teaching? Rethinking Curriculum in the Age of Technology, New York and London: Teachers College Press.

Deutscher, G. (2011). THROUGH THE LANGUAGE GLASS WHY THE WORLD LOOKS DIFFERENT IN OTHER LANGUAGES, New York: Henry Holt and Company.

Fallow, D. (2010). DREAMING in CHINESE MANDARIN LESSONS IN LIFE, LOVE, AND $L A N G U A G E$. New York: Walker \& Co.

Jackson, S.E., May, K.E., \& Whitney, K. (1995). Understanding the Dynamics of diversity in DecisionMaking Teams. Team Effectiveness and Decision Making in Organizations, 204-261. San Francisco: Jossey-Bass.

Judson, E. (2006). How Teachers Integrate Technology and Their Beliefs about Learning: Is There a Connection? Journal of Technology and Teacher Education, 14(3), 581-597.

Kalambakal, V. (2018). The Advantages of Being an Older Student. Back to College, 22.

Moreno, A.E.I. (2001) Native speaker - Non-native speaker interaction: the use of discourse markers. ELIA, 2, 129-142.

Noroozi, O., \& Hatami, J. (2018). The effects of online peer feedback and epistemic beliefs on students' argumentation-based learning. Journal of Innovations in education and Teaching International, $25,1-10$.

Scott, R.W. (2015). HIGHER EDUCATION IN AMERICA Multiple Field Perspectives. REMAKING college THE CHANGING ECOLOGY OF HIGHER EDUCATION, 19-38. Stanford University Press.

Settersten, R.A. Jr. (2015). The new landscape of early adulthood implications for broad-access higher education. REMAKING college THE CHANGING ECOLOGY OF HIGHER EDUCATION, 113133. Stanford University Press.

Wood, M. (2017). Foreign Language Classrooms: Native versus Non-Native Teachers and Culture Integration. the OFKA-Cardinal.org.

Herrmann, E. (2018). Help or hindrance? Use of native language in the English classroom. MULTIBRIEFS EXCLUSIVE CONTENT.

Peng, T.H. (2005). What's in a Chinese Character. Singapore: Times Editions-Marshall Cavendish. 


\section{APPENDIX}

The rich and diverse backgrounds - A summary of 100 example students from different years

1) Attended Texas A\&M University to pursue postgraduate work in government policy as a fellow at the Scowcroft Institute of International Affairs.

2) Work as a software engineer and systems integrator specializing in web application development and back-end architecture development for Lawrence Livermore National laboratory

3) A developer, IT service manager, and development team leader

4) Airborne Systems Engineer in the United States Air Force and IBM data center technician

5) A sophomore at Santa Clara University

6) Attended High School in Shanghai, China but never learned Chinese there. Currently studying Applied Mathematics.

7) Work as a lifeguard and a swim instructor at a gym, and an assistant swim coach for a swim team; A swim instructor at a local water park (Aqua Adventure)

8) Work full time in the Logistics field

9) A Network Engineering Technical Program Manager at Facebook on a team's mission to connect everyone in the world with internet

10) A psychology major currently working at Massage Envy as a front desk and help clients check in and check out

11) Worked at a Grocery Outlet and the Great America amusement park

12) A Silicon Valley Engineer and works in sales as well

13) Aviation Port Service worker at Norman Y. Mineta San Jose Airport

14) Legal receptionist at a law office

15) Buddhist practitioner

16) Full-time worker at a computer networking company

17) Package handler for FedEx

18) From New Zealand

19) Head engineer for commercial LCD display company in Fremont

20) Retired Army Lieutenant Colonel who served in Iraq

21) Retired attorney

22) Former employee at Alcatel-Lucent Shanghai Bell

23) Chemical engineer at a Japanese company in Sunnyvale

24) From Panama

25) A single mother of six 'really awesome kids', built orphanages while living overseas, a published author of 'Saving Levi'

26) Registered nurse of 20 years

27) A Business Administration major in CSUEB

28) Small business owner who imports clothing from south east Asia

29) A respiratory therapist in Kaiser Permanente

30) Former TJMAXX employee who majored in theatrical lighting design

31) Interior Design major

32) Khmer speaker from Cambodia

33) Dance instructor also enrolled at the University of Redlands and the College of Marin 
34) An English major at UC Berkeley

35) Restaurant / café waiter / barista with experiences in styles ranging from Korean, to vegan, to Italian, and milk tea

36) A personal trainer and physical therapist

37) Graduated from Sichuan Business School

38) Half-Taiwanese, born in Thailand

39) A sales person for an international trading company

40) A major in graphic design

41) Came from Taiwan and majored in accounting

42) From Vietnam and works part-time at Ross

43) Worked at Gong Cha - a bubble tea place in Fremont

44) A history major and part-time painter who refurbishes rental properties

45) Worked for Rising Sun Energy Center installing energy efficient light bulbs in people's homes

46) Transferred to Ohlone College from Jeju National University in South Korea

47) Works for own trading company importing and exporting between China and Korea

48) Works as a supervisor and tutor at dad's Berkeley Academy after school program

49) Former faculty at the University of Damascus (Syrian and Italian descent). Ph.D. in Biology.

50) Homeschooled and a volunteer at Washington Hospital in Fremont

51) Graduated from Yangzhou High School that the former President of PRC, Jiang Zemin, attended

52) A strategic account manager for Reflex Packaging, contracted manufacturing in various parts of China and focused communication towards employees in Shanghai and Dongguan

53) A teacher's aide for architect courses

54) Worked in Sogo Bakery and now a full-time student at Berkeley

55) Acupuncturist assistant

56) Former firefighter of 12 years

57) Worked for a Korean bakery

58) Teacher of Korean in Korean academy

59) Of Philippine descent, studying Criminology

60) Target cashier

61) Former accountant at UC Berkeley

62) Executive assistant at start-up

63) Graduate from Singaporean high school who also attended community college in Houston

64) Graduate from Japanese high school

65) Born in Ho Chi Minh city and grew up in a Vietnamese-Chinese family

66) Barista at local Starbucks

67) Work part-time at Menchie's Frozen Yogurt in Mowry Shopping Center

68) Lifeguard from Tennessee

69) Public servant who graduated from UC Berkeley

70) Developer at Image Games Network (IGN) in San Francisco and other tech companies 
71) A martial arts coach at California Wushu Academy

72) A tennis coach

73) TA for $4^{\text {th }}$ grade at after school program

74) Burmese and Shan speaker from the University of Computer Science Yangon

75) CFO for mom's culinary business

76) Tagalog speaker who studied at Far Eastern University in the Philippines

77) Has a M.S. degree in Sustainable Engineering at University of Strathclyde in Glasgow, Scotland and work in Sustaining Engineering at Tesla

78) Born in Japan and spent most of life time in Hong Kong and graduated from Samuel Merritt University

79) Have worked in the medical diagnostics industry for over 20 years in a variety of roles most recently in inventory management

80) Fellow Ohlone faculty with English teaching experience in China

81) Assistant speech and debate coach who was homeschooled

82) Studied in a Malaysian University before coming to Ohlone

83) A full-time worker in the field of manufacturing to import and export

84) Worked as a CNA certified nursing assistant in the past, and currently work at a FedEx Ground warehouse to move, label, patch up, scan, and load packages into trucks

85) A machinist and a blacksmith

86) Medical assistant at a local hospital in Fremont

87) Completed Associate of Applied Science in Pharmacy Technology at Heald College. Studying at Azusa Pacific University in Los Angeles finishing Bachelor's in Science in Biochemistry.

88) An occupational therapist at a skilled nursing facility

89) Part of the Seishinkan Kyudojo located in the San Jose area

90) Part-time worker at Dollar Tree and Amazon

91) A waiter at a Korean BBQ place (Beque in Newark)

92) Special education elementary school teacher for $3^{\text {rd }}-5^{\text {th }}$ grades.

93) Transferred to UCLA and received a bachelor degree in Business Economics major and Accounting minor

94) Work full-time as a General Ledger accountant in a financial company in San Mateo

95) Full time as a technician for medical devices

96) Inventory controller

97) Employee at Sno-Crave Tea House and Ultra Karaoke Music Studio

98) Graduated from Queen Elizabeth School Old Students' Association Secondary School in Hong Kong

99) Student at San Jose State University

100) A career \& job counselor at Columbia College in Sonora, CA 